\title{
Acoustical performance of porous absorber made from recycled rubber and polyurethane resin
}

\section{Abstract}

This paper reports an investigation of a new kind of material and its acoustical performance. The main component of this porous absorber is the ground tyre rubber (GTR) with different particle sizes, from the shredding of tyres of heavy vehicles, mixed with different proportion of polyurethane resin. Acoustical properties were assessed according to ISO 10534-2: 1998. The data obtained show porous absorbers having a high sound absorption performance with low thicknesses and compared to some of the current models for the prediction of their absorptive properties. The use of this model constitutes a good tool in order to design a new sound absorber to solve two environmental problems, noise and environmental pollution.

\section{Keywords}

Sound absorber; Recycler rubber; Acoustical properties; Impedance tube; Impedance measurement.

\author{
Rubén Maderuelo-Sanz ${ }^{* a}$, \\ Juan Miguel Barrigón Mori- \\ llas ${ }^{b}$, Manuel Martín-Castizo ${ }^{a}$, \\ Valentín Gómez Escobar ${ }^{b}$ and \\ Guillermo Rey Gozalob \\ ${ }^{a}$ Instituto Tecnológico de Rocas Ornamentales y \\ Materiales de Construcción, INTROMAC, Cam- \\ pus Universidad de Extremadura, 10071, Cáce- \\ res, Spain,

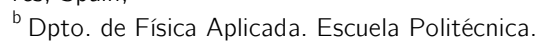 \\ Universidad Extremadura, 10003, Cáceres, Spain \\ Received 19 Apr 2012 \\ In revised form 30 Nov 2012 \\ Author email: rmaderuelo@intromac.com
}

\section{INTRODUCTION}

The improvement on the human quality of life and the continuous growth in population in developing and developed societies, have exacerbated the environmental and financial problems. Some of these problems are noise and the different types of human an industrial wastes.

There have been numerous studies concerning noise, its sources, pollution levels, effects, human health, etc., over the last years, and the topic is still of medical and scientific interest as shown by the different studies published in recent years like in Zannin et al. (2002), Murphy and King (2011), Barrigón-Morillas et al. (2010) and Jakovljevic et al. (2009). In the case of industrial wastes, in the last years disposal of scrap tyres has became one of the major environmental problems. The European Tyre Recycling Association, ETRA, showed in Tyre Technology International - Trends in Tyre Recycling (2006) that over 3 million tons of waste tyres are generated in the United States and $\mathrm{Li}$ et al. (2010) that 5.2 million tons are generated in China each year.

The amount of waste tyres is increasing due to the highest demand for tyres and their short lifetime. It is therefore necessary to improve or to develop certain process or applications for recy- 
cling waste tyres. Li et al. (2010) show that nowadays there are many methods to treat and to reuse end of life tyres (ELTs): retreading; ambient grinding; dynamic devulcanization; pyrolysis and tyre oil extraction. Other option is the material recovery; at this aim, a waste tyres shredding process, generally followed by an electromagnetic separation allows to recycle both rubber particles and steel fibres. For example, Aiello et al. (2009) show that the use of steel fibres from waste tyres as reinforcement in concrete has shown interesting potentiality, because of their ability to improve the mechanical performances of the concrete similarly to industrial steel fibres.

Other types of uses are associated to acoustical researches as show the work of Oldham et al. (2011). There are currently a lot of researches interested in developing sustainable absorbers from recycled materials such as crumb rubber. The use of this type of waste to produce sound absorbers or resilient underlays could solve two environmental problems, noise and environmental pollution.

Some studies have proposed to use recycled tyres to provide alternatives to existing products in a great number of environmental noise control applications. Recent studies from different authors have shown that recycled polymeric granulates from the recycling of products from end of life tyres may be formed into materials that have desirable acoustical properties. Pfretzschner and Rodríguez (1999) and Rodríguez Montejano (2004) verified that rubber crumbs can be a good sound absorber with a broadband absorption spectrum, being an excellent alternative to the current absorbent screens used for the protection against traffic noise, contributing at the same time to eliminate scrap tires. Swift et al. (1999) found that these materials can effectively absorb sound if the size of the aggregate and the binder content are carefully selected and its thickness is tuned to the frequency range of interest. Hong et al. (2007) showed that a new sound absorber with recycled rubber particles presents good attenuation properties as sound energy attenuation layer including low-cost, broad-band sound absorption, thin in thickness and relatively simple processing. Another study conducted by Jimenez-Espadafor et al. (2011) suggested that the waste tyre textile (fluff) could be mixed in the same proportion with hot melt adhesive to produce a real acoustic ceiling tile with a very high absorption coefficient. Horoshenkov and Swift (2000) showed that the application of the binder has considerable effect on the acoustical properties of the rubber granular mix. In the case of improvements on the traffic noise, Paje et al. (2010) showed that the acoustical performance of pavement surfaces made from bituminous mixtures, fabricated with recycled tyres (incorporating crumb rubber as aggregate), managed to reduce the noise reduction up to $2 \mathrm{~dB}(\mathrm{~A})$ and Han et al. (2008) verified that crumb rubber blends present a potentially viable alternative to current concrete highway noise barriers.

In the case of impact sound insulation, the works of Maderuelo et al. (2011) and Rushforth et al. (2005) showed that the underlays, made from recycled rubber fluff or produced using the optimum grain/fibre ratio, respectively, presented excellent sound insulation performance in impact loading comparables with some commercial products.

The purpose of this paper is to experimentally investigate the acoustical properties of new porous absorbers made from granulated rubber from automotive tyres and to use the experimental results obtained in the laboratory, using an impedance tube, to develop a new sound absorber. This granulated rubber from automotive tyres can be mixed in different conditions, binder or adhesive content, to obtain an improvement in the sound absorption coefficient of these sound absorbers.

Latin American Journal of Solids and Structures 10(2013) $585-600$ 
Subsequently, a comparison with some of the current models for predicting their performance was conducted.

\section{MODELLING OF THE MATERIALS}

Many models have been developed to describe wave propagation in porous materials and are used to predict the acoustical performance of air saturated sound absorbing porous media. Some of these models, based on the assumption of rigid frame media, describe the physical phenomena that govern the energy dissipation in the porous media. These models have some non acoustical parameters, porosity, tortuosity, flow resistivity, etc. that can be obtained with non-acoustically methods. In these models two complex quantities, the equivalent dynamic bulk modulus and the equivalent dynamic density describe the acoustical properties of the porous absorber. The mechanisms of absorbing sound inside the porous media are the energy dissipated due to the heat exchange and the viscous friction in the effective fluid in the porous structure. The equivalent dynamic density treats the visco-inertial dissipation in the media and the equivalent dynamic bulk modulus takes into account the thermal dissipation effects.

The theoretical model proposed by Champoux and Stinson (1992) shows the best approximations between experimental and theoretical results in this type of material as shows the work of Pfretzschner and Rodríguez (1999). This model involves the flow resistivity, porosity, tortuosity and two shape factors by comparing predicted behaviour to experimentally determined results. Equation (1) is the expression of the dynamic fluid density of rigid frame materials proposed by Biot(1956):

$$
\rho(\omega)=\rho_{0} \alpha_{\infty}-\left(\frac{i \sigma \Omega}{\omega}\right) \cdot F\left(\lambda_{p}\right)
$$

where $\rho_{0}$ is the density of the air, $\alpha_{\infty}$ is the tortuosity, $\Omega$ the porosity, $\omega$ is the angular frequency where:

$$
F\left(\lambda_{p}\right)=-\frac{1}{4} \cdot \frac{\lambda_{p} \sqrt{-i} \cdot T\left(\lambda_{p} \sqrt{-i}\right)}{\left[1-2 T\left(\lambda_{p} \sqrt{-i}\right) / \lambda_{p} \sqrt{-i}\right]}
$$

with

$$
\lambda_{p}=s_{p}\left(\frac{8 \alpha_{\infty} \rho_{0} \omega}{\sigma \Omega}\right)^{1 / 2}
$$

where $\mathrm{T}(\xi)=\mathrm{J}_{1}(\xi) / \mathrm{J}_{0}(\xi)$ is the ratio between Bessel functions of first and zero order. 
Eq. (4) shows the equation of the dynamic bulk modulus of the fluid of rigid frame materials proposed by Zwikker and Kosten (1949) used by Champoux and Stinson (1992) in their model:

$$
K(\omega)=\frac{\gamma P_{0}}{\left(1+\frac{2(\gamma-1)}{N_{p r}^{1 / 2} \lambda_{k} \sqrt{-i}} \cdot T\left(N_{p r}^{1 / 2} \lambda_{k} \sqrt{-i}\right)\right)}
$$

with:

$$
\lambda_{k}=s_{k}\left(\frac{8 \alpha_{\infty} \rho_{0} \omega}{\sigma \Omega}\right)^{1 / 2}
$$

In the equations (1) to (5), $\rho_{0}$ is the density of the air, $\sigma$, the flow resistivity, $\omega$, the angular frequency, $\mathrm{i}^{2}=-1, \gamma$, the fluid specific heat ratio, $\mathrm{N}_{\mathrm{Pr}}$, the Prandtl number of the air, $\mathrm{P}_{0}$, the atmospheric pressure and, $s_{\mathrm{p}}$ and $\mathrm{s}_{\mathrm{k}}$ are the cross-sectional shape factors of the pore defined by Champoux and Stinson [19].

The sound absorption properties of porous materials are determined by the characteristic impedance $\mathrm{Z}_{\mathrm{c}}(\omega)$, the complex wave number $\mathrm{k}_{\mathrm{c}}(\omega)$, the surface acoustic impedance $\mathrm{Z}_{\mathrm{s}}$ and the absorption coefficient $\alpha$ (Equations 6-9):

$$
\begin{gathered}
Z_{c}(\omega)=\frac{1}{\Omega} \sqrt{\rho(\omega) \cdot K(\omega)} \\
k_{c}(\omega)=\omega \sqrt{\rho(\omega) / K(\omega)} \\
Z_{s}=-i Z_{c}(\omega) \cdot \cot \left(k_{c}(\omega) d\right) \\
\alpha=1-\left|\frac{Z_{s}-Z_{0}}{Z_{s}+Z_{0}}\right|^{2}
\end{gathered}
$$

where $\mathrm{Z}_{0}$ is the impedance of the air and $\mathrm{d}$ is the thickness of the sample.

\section{MATERIALS}

In previous work, the works of Maderuelo et al. (2011) and Rushforth et al. (2005) demonstrated that elastomeric waste, called ground tyre rubber, can be recycled into acoustical underlay products that can adequately compete with commercially available acoustical products and, in some cases, having better performance than conventional layers in terms of their acoustical properties. Those 
types of samples have been tested as a new sound absorber, using recycled rubber particles with different proportion of binder.

The main raw material used for this work was the ground tyre rubber, with different particle sizes, coming from the shredding of tyres from vehicles. Other materials used in the samples were vermiculite and expanded polystyrene (EPS) as it can see in Figure 1.

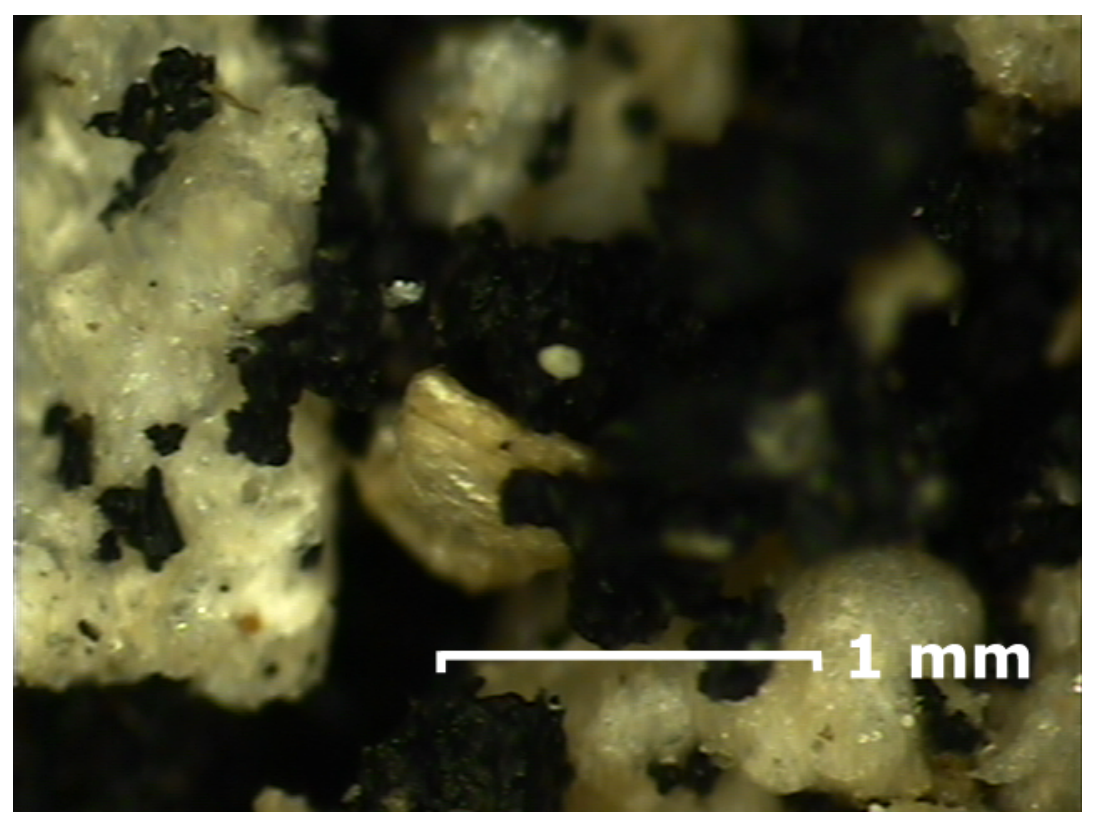

Figure 1 Microphoto of sample M-1 obtained with Mitutoyo Vision Machine. Particle of rubber, EPS and vermiculite can be observed.

A high viscosity polyurethane resin (SikaBond T53 manufactured by Sika), in a range of proportions of $5-25 \%$, was used as a binder to mix these materials. This kind of resin was used because of its high viscosity. The use of binders with low viscosity is not recommended because they reduce the porosity and make it very difficult to mix the rubber fluff with the binder efficiently. Table 1 shows the formulations of the new sound absorbers samples with their physical properties.

Table 1 Properties of recycled porous absorbers.

\begin{tabular}{lcccccc}
\hline \hline Sample & $\begin{array}{c}\text { GTR Grain } \\
\text { Size (mm) }\end{array}$ & $\begin{array}{c}\text { Sample Compo- } \\
\text { nents }\end{array}$ & $\begin{array}{c}\text { Density } \\
\left(\mathbf{k g} / \mathbf{m}^{\mathbf{3}}\right)\end{array}$ & $\begin{array}{c}\text { Binder Con- } \\
\mathbf{c e n t r a t i o n} \\
\mathbf{( \% )}\end{array}$ & $\begin{array}{c}\text { Thickness } \\
\mathbf{A}(\mathbf{m m})\end{array}$ & $\begin{array}{c}\text { Thickness } \\
\mathbf{B}(\mathbf{m m})\end{array}$ \\
\hline M-1 & $<2.0$ & GTR/Vermiculite/EPS & 408.7 & 5 & 14.0 & 26.5 \\
M-2 & $<3.5$ & GTR (75\%) & 526.6 & 25 & 14.0 & 28.5 \\
M-3 & $0.5-1.0$ & GTR (80\%) & 559.8 & 20 & 16.0 & 30.0 \\
M-4 & $1.0-3.0$ & GTR (88\%) & 547.6 & 12 & 16.5 & 29.5 \\
M-5 & $1.0-3.0$ & GTR (84\%) & 554.7 & 16 & 17.0 & 31.5 \\
M-6 & $0.5-1.0$ & GTR (84\%) & 594.6 & 16 & 14.0 & 29.0 \\
M-7 & $<0.5$ & GTR (80\%) & 520.0 & 20 & 17.5 & 32.5 \\
\hline \hline
\end{tabular}


The manufacturing process is easy, all components were mixed in their respective proportions, as shown in Table 1 , in the temperature range of $20-30^{\circ} \mathrm{C}$ and this mixture was applied with an airless gun with a special tip, cited by Maderuelo-Sanz et al. (2011). The test specimens were circular, with two different thicknesses for each sample (29 and $100 \mathrm{~mm}$ in diameter).

\section{EXPERIMENTAL METHODOLOGY}

\subsection{Physical properties}

Porosity

Porous materials with open cells consist of an elastic or rigid frame which is surrounded by air. The porosity, $\Omega$, is the ratio of the air volume, inside the sample, to the total volume, occupied by the porous material.

The connected porosity was measured non-acoustically using the method of water saturation as indicated by Vasina el al. (2006). All samples were dried at $50{ }^{\mathrm{o}} \mathrm{C}$ for 30 days. Then, they were weighed before being wrapped in a thin water-tight film and left under water (the density of water is $\rho_{\mathrm{w}}=1000 \mathrm{~kg} / \mathrm{m}^{3}$ ) in a vacuum vessel to saturate. After $24 \mathrm{~h}$, they were carefully removed and weighed again. The porosity was computed by the equation $(10)$, where $\mathrm{V}_{\mathrm{w}}$ is the volume in the sample occupied by the water and $V_{S}$ is the total volume of the sample. The volume of water can be found as $V_{\mathrm{w}}=\left(\mathrm{m}_{\mathrm{wet}}-\mathrm{m}_{\mathrm{dry}}\right) / \rho_{\mathrm{w}}$, where $\mathrm{m}_{\mathrm{wet}}$ and $\mathrm{m}_{\mathrm{dry}}$ are the wet and dry masses of the sample, respectively:

$$
\Omega=\frac{V_{w}}{V_{s}}
$$

\section{Flow resistivity}

The flow resistivity is one of the most important defining characteristics and is determined by the porosity and the pore size, being the latter dependent on the size and shape of the grains. There are several empirical and semi-empirical models in technical literature, in order to estimate airflow resistivity on the basis of various parameters, binder concentration, compaction ratio, porosity, etc.

In this work, Equation (11) is used for predicting the flow resistivity of the samples. This expression, used for consolidated elastic rubber granulates, showed previously by Horoshenkov and Swift (2000), show an empirical dependence between the binder concentration and the flow resistivity:

$$
\log _{10} \sigma=3.074 \beta+3.794
$$

where $\beta$ is the mass binder concentration and $0 \% \leq \beta \leq 30 \%$. 


\section{Tortuosity}

The tortuosity $\alpha_{\infty}$ is an adimensional structural parameters and shows the influence of the internal pore structure on the macroscopic velocity of the fluid flow through the material. It has a value which depends only on the pore geometry, as show Johnson et al. (1982), and the minimum possible value is 1 .

The tortuosity was measured non-acoustically using the method indicated by Brown (1980). This method is based in an electroacoustical analogy through the electrical conductivity of a saturating fluid. The porous material is saturated with a conducting fluid (a $10 \%$ dissolution of $\mathrm{CuSO}_{4}$ ), and the electrical resistivity (equivalent to the flow resistivity) is then calculated through current and voltage measurements (using circular plates of copper as electrodes.) like in Pfretzschner and Rodríguez (1999).

Having $\rho_{\mathrm{c}}$ and $\rho_{\mathrm{f}}$ the measured resistivities of the saturated material and the fluid respectively, the tortuosity is given by the next expression:

$$
\alpha_{\infty}=\Omega \cdot \frac{\rho_{c}}{\rho_{f}}
$$

where porosity, $\Omega$, is the connected porosity of the sample.

\subsection{Acoustical properties}

To evaluate the acoustical properties of different samples (the surface impedance and sound absorption coefficient), measurements of the sound absorption characteristics were carried out using an impedance tube. The impedance tube measurements are based on the two-microphone transferfunction method according to the standard procedure detailed in ISO 10534-2 (1998) in the frequency range of 100-6400 Hz. Using this method it is possible to obtain fast measurements of normal incident parameters using small samples.

The impedance tube method has a great number of advantages as show Oldham et al. (2011). First, the apparatus itself is small and therefore practical. Secondly, only a small sample is required for the tests, and thirdly it allows the surface impedance to be determined in addition to the absorption coefficient. The disadvantages are first, that the properties are only measured for sound at normal incidence to the sample although it is possible to apply a correction, from the surface impedance values, to obtain an approximate value of the random incidence absorption coefficient. Secondly, uncertainties are introduced when measuring heterogeneous materials as the constitution and pore structure of samples taken from different regions of a large sample may vary considerably. Thirdly, two different tubes, and subsequently two different samples, are required for measurements over a large frequency range.

The measurements were made using the Brüel\&Kjær Impedance Tube Kit Type 4206 and two $\frac{1}{4}$ " Condenser Microphones Type 4187. The signals were analyzed with a portable Brüel\&Kjær PULSE System with four input data channels (type 3560-C). Sample holders of $100 \mathrm{~mm}$ and $29 \mathrm{~mm}$ 
in diameter are provided; the first is employed for measurements over the range of frequencies from $50 \mathrm{~Hz}$ to $1.6 \mathrm{kHz}$ and the latter over the range of frequencies from $500 \mathrm{~Hz}$ to $6.4 \mathrm{kHz}$.

\section{RESULTS}

\subsection{Non-acoustic properties}

Large differences were observed in the porosity values due to the different microstructures of the samples. This diversity is very interesting because it can provide very different porous microstructures and consequently different acoustical properties. The porosity is distributed between pores of different sizes (ranging from $1 \mu \mathrm{m}$ to $1 \mathrm{~mm}$ ) into and between the particles and in the binder. The values obtained are shown in Table 2 .

Table 2 Non acoustic properties of different samples.

\begin{tabular}{|c|c|c|c|}
\hline Sample & Porosity & Tortuosity & Flow Resistivity $\left(\mathrm{Pa} \mathrm{s} \mathrm{m^{-2 }}\right)$ \\
\hline M-1 & 0.617 & 2.749 & 8865 \\
\hline M-2 & 0.600 & 1.580 & 36517 \\
\hline M-3 & 0.360 & 1.880 & 25633 \\
\hline M-4 & 0.535 & 2.402 & 14551 \\
\hline M-5 & 0.472 & 1.303 & 19313 \\
\hline M-6 & 0.589 & 1.635 & 19313 \\
\hline M-7 & 0.310 & 1.291 & 25633 \\
\hline
\end{tabular}

With the exception of the samples M-2 and M-6, the porosity decreases when the binder concentration increases. Sample M-1 presented higher values of porosity because of the composition of the composite. Vermiculite and EPS (Figure 1) contributed to the porosity with micropores, and their presence resulted in the increased overall porosity of the granular mix. The GTR grain size, a high proportion of large grains, and the proportion of binder in Sample M-2 determined the value of its porosity. Samples M-3 and M-7 presented a similar porosity attributed to a relatively high proportion of binder and the grain size in the mix. This low porosity is due to the voids between individual grains that were filled by the binder. In the other samples the porosity is similar because, although the proportion of binder is different, sample M- 6 has more proportion of binder than the sample M-4, in the latter; the size of the particles in the granular mix is different so the voids are not identical in size and proportion.

The flow resistivity is determined by the porosity, the binder concentration and the pore size, and the latter is dependent on the size and shape of the pores. The range of flow resistivities, calculated using the Horoshenkov-Swift model for loose rubber granulates, is from 8.865 to $36.517 \mathrm{~Pa} \mathrm{~s}$ $\mathrm{m}^{-2}$. The values obtained are shown in Table 2 . The flow resistivity progressively increases with the increasing of the binder concentration for consolidated mixes with particle size in the range 0-6 mm as show Swift et al. (1999). Figure 2 shows that reducing the porosity results in an increased flow resistivity. This adversely affects the overall acoustic performance of the granular mix.

Latin American Journal of Solids and Structures 10(2013) $585-600$ 


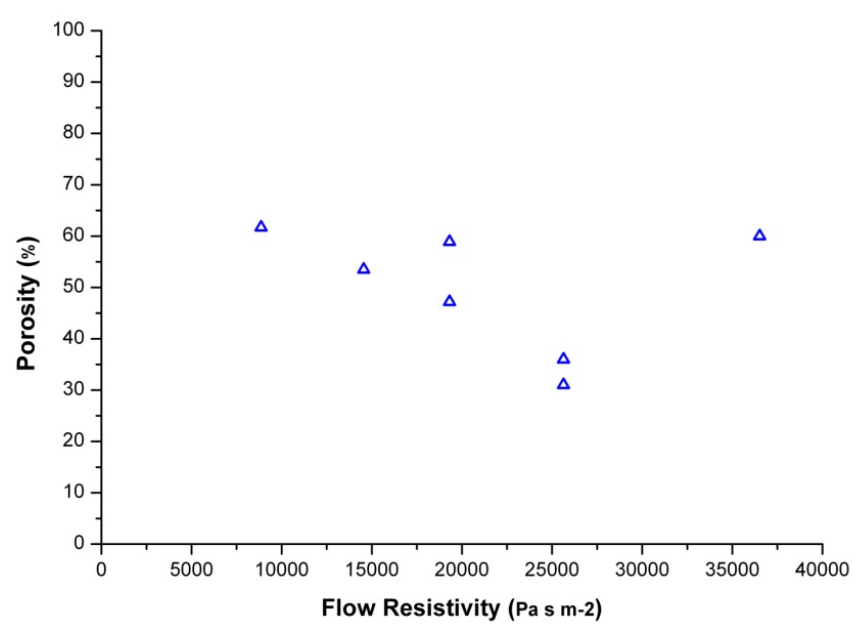

Figure 2 The porosity as a function of the flow resistivity for the samples of GTR.

The values of tortuosity for each sample, corresponding to saturation of the samples by a $10 \%$ dissolution of $\mathrm{CuSO}_{4}$, are shown in Table 2. These measurements have been made using direct voltage (d.c. power supply). It was found very good linearity of the experimental points in all the samples (Figure 3).

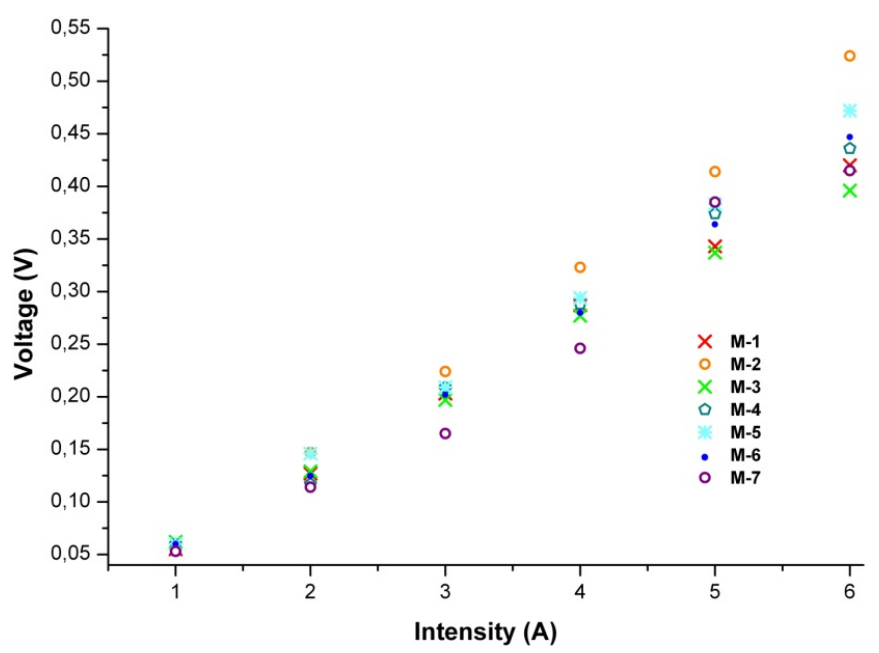

Figure 3 The voltage as a function of the intensity for the samples, obtained non acoustically using the method indicated by Brown [25].

Table 3 shows the equation of the straight line which provide a best fit for the data points or the line that minimizes the sum of squared residuals of the linear regression model. Table 2 shows large differences in their tortuosity values due to the different microstructures of the samples. The range of the tortuosity is from 1.291 to 2.749 . It may be pointed out that this range of tortuosity can be the result of constrictions of the pores as well as changes in their orientation or the binder concen- 
tration. The high value of tortuosity for the sample M1, as well as the porosity, is due to the composition of this sample (GTR, Vermiculite and EPS).

Table 3 Equations of the straight line which provide a best fit for the data points for each sample in this work, where $X$ is the intensity $(A)$.

\begin{tabular}{lcc}
\hline \hline Sample & Linear Regresion Model & $\mathbf{R}^{\mathbf{2}}$ \\
\hline M-1 & $0.0731 X-0.0165$ & 0.9981 \\
M-2 & $0.0929 X-0.0440$ & 0.9977 \\
M-3 & $0.0678 X-0.0044$ & 0.9980 \\
M-4 & $0.0780 X-0.0257$ & 0.9965 \\
M-5 & $0.0816 X-0.0249$ & 0.9974 \\
M-6 & $0.0780 X-0.0247$ & 0.9983 \\
M-7 & $0.0773 X-0.0407$ & 0.9915 \\
\hline \hline
\end{tabular}

\subsection{Acoustical properties}

It has been known that the acoustic absorption behaviour of a porous material depends on the porosity, the tortuosity, the flow resistivity and on the thickness of the layer. When the sound propagates in the interconnected pores of a porous material, energy is lost. This lost of energy is due to the complex heterogeneous microstructure and the viscous boundary layer effects (the surface of interactions between the two phases through viscous and thermal losses. The air is a viscous fluid so sound energy is dissipated via friction with the pore walls. As well as viscous effects there are losses due to thermal conduction from the air to the porous material although is more important at low frequencies. As the thickness of the samples increases, the absorption at low frequency usually increases.

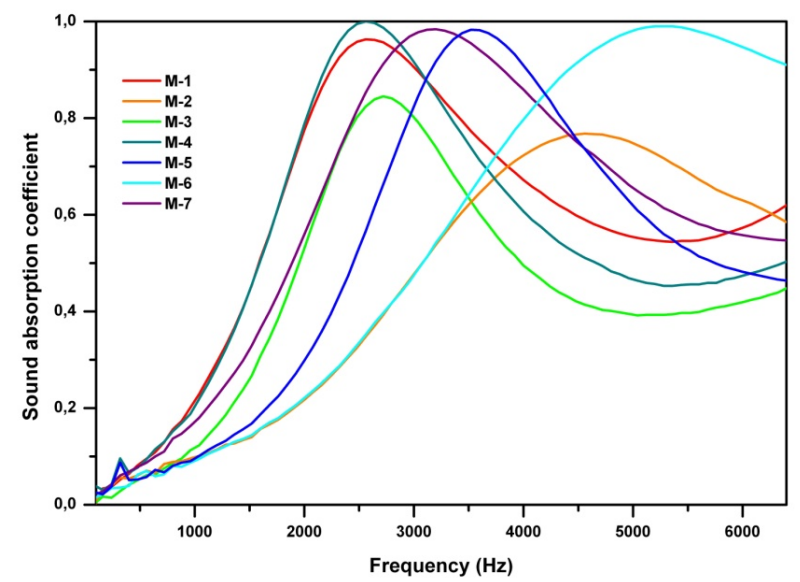

Figure 4 Sound absorption coefficient for the samples with the thickness $A$ 




Figure 5 Sound absorption coefficient for the samples with the thickness B.

Two thicknesses for each sample were tested (Figures 4 and 5). Figure 4 shows the normal sound absorption coefficient spectra for the samples with the thickness A. These results show that the best acoustic performance over the frequency range of interest is obtained for the samples M-1 and M4. For these samples the maximum value of the sound absorption coefficient is 1.00 and 0.96 , respectively, achieved at the same frequency, $2560 \mathrm{~Hz}$. Both samples show similar performance with the difference in their thickness, 14.0 and $16.5 \mathrm{~mm}$ and their porosity, 0.617 and 0.535 , respectively.

It is obvious that $14.0 \mathrm{~mm}$ of porous absorber of GTR with the grain size $<2.0 \mathrm{~mm}$, vermiculite and EPS and consolidated with $12 \%$ binder concentration can yield the highest absorption coefficient values in the broader frequency range for the selected samples of porous absorber. This is attributable to the higher porosity and tortuosity due to the micropores of vermiculite an EPS.

The porosity values for samples M-3 and M-7 are similar. There is a small difference due to the particle size. The binder concentration for these two samples is the same. In the case of material M3 , a higher thickness and a sudden increase in the value of tortuosity implies a shift of the maximum absorption coefficient at frequency $2600 \mathrm{~Hz}$. The value of the sound absorption coefficient achieved at this frequency is 0.86 . The sample M-7, with lower thickness and value of tortuosity than sample M-3, presents a maximum absorption coefficient at frequency of $3220 \mathrm{~Hz}$ with a value greater than latter, 0.98 . The acoustic performance of the sample M-5 is similar to the sample M-7, showing the maximum absorption coefficient at frequency $3560 \mathrm{~Hz}$.

Samples M-2 and M-6 show similar non-acoustic properties. The proportion of binder in sample M-2 is higher than sample M-6. Sample M-6 present better acoustic performance than sample M-2 and may be due to the higher value of tortuosity and thickness.

Figure 5 shows the normal sound absorption coefficient spectra for the samples with the thickness B. It is obvious that the most evident effect of increasing the thickness of the samples is to shift the normal absorption curve to lower frequency values. This new thickness may not result in better acoustic performance, so we can think that there is a thickness that takes into account the visco-thermal effects with the structure of the material as show Swift et al. (1999). 
Figures 6 and 7 show, respectively, the real and the imaginary part of the normalized acoustic impedance obtained from the different samples and the thickness A. The real part is the resistance associated with energy losses and the imaginary part, the reactance, associated with phase changes. In this case, we can see a better performance of materials M-1 and M-4 than other materials studied in this work.

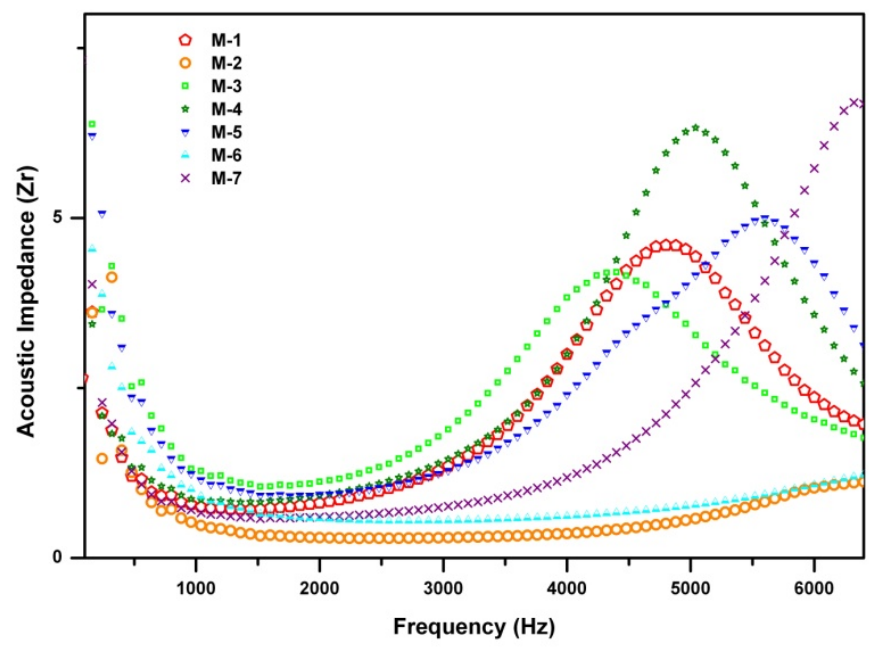

Figure 6 Real part of acoustic impedance from the samples with the thickness A.

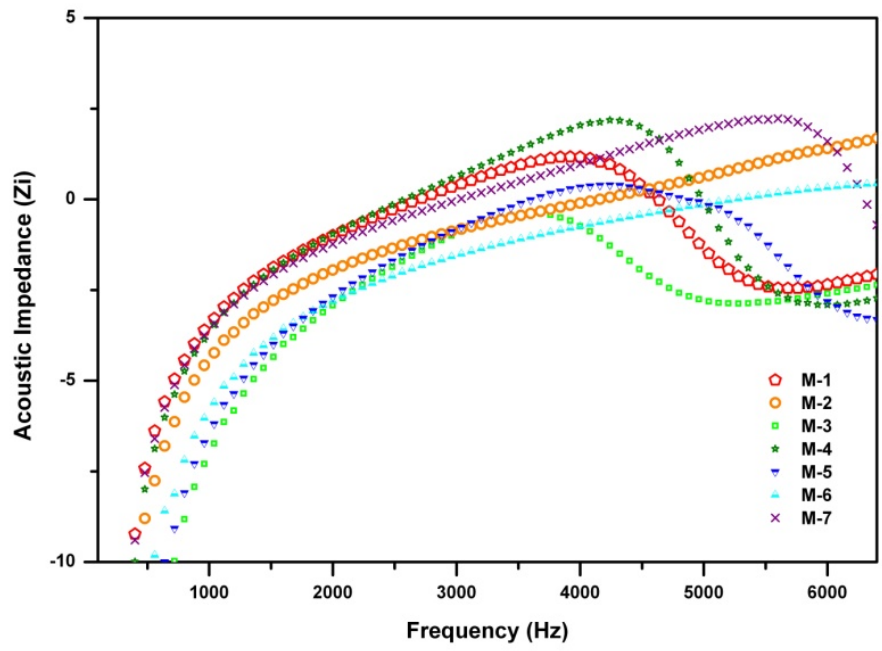

Figure 7 Imaginary part of acoustic impedance from the samples with the thickness A.

The value of the maximum in the real part of the impedance of the samples M-1, M-3 and M-4 is reduced in comparison with the other samples. This results in an increased absorption coefficient values in the vicinity of the maximum of sound absorption coefficient as we can see in Figure 4. 
The real and the imaginary part of the normalized acoustic impedance are shifted towards the low frequency and this is results of the increasing tortuosity values of this samples. In case of the samples M-2 and M-6, the value of the maximum in the real part of the impedance is shifted towards the high frequency so this results in low values of acoustic absorption.

\subsection{Theoretical modeling}

In order to design acoustic material adequate for using as a porous absorber, it is appropriate to predict the acoustical absorption in accordance with the frequency. Nowadays a great number of models are available for predicting the acoustical characteristics of porous absorbers, saving time and a lot of experimental testing.

Models for porous absorbers, with complex pore structures, require more detail to account for the interaction between the sound waves and the pores of the material. Modeling of the acoustic properties of the samples used in this work was carried out using the model described in the equations 1-9. This model requires five parameters; flow resistivity, porosity, tortuosity and two shape factors. Three first parameters are obtained non-acoustically and the shape factors by comparing predicted behavior to experimentally determined results.

The comparison between the theoretical model and the experimental results are show in Figures 8 and 9 for samples M.1 and M-4 respectively. The measured and predicted absorption coefficient for sample M-4 with two thicknesses, 29.5 and $16.5 \mathrm{~mm}$, is shown in Figure 9. The predicted results for this sample follow closely the experimental result practically throughout the considered frequency range. Two different shape factors are required for this porous material. This is the demonstration that the dynamic density and the dynamic bulk modulus are associated with the pore geometry. The best fit values for this sample are $s_{p}=2.590$ and $s_{k}=0.285$. Agreement between theory and experimental results are essentially perfect for frequencies higher than $1000 \mathrm{~Hz}$.

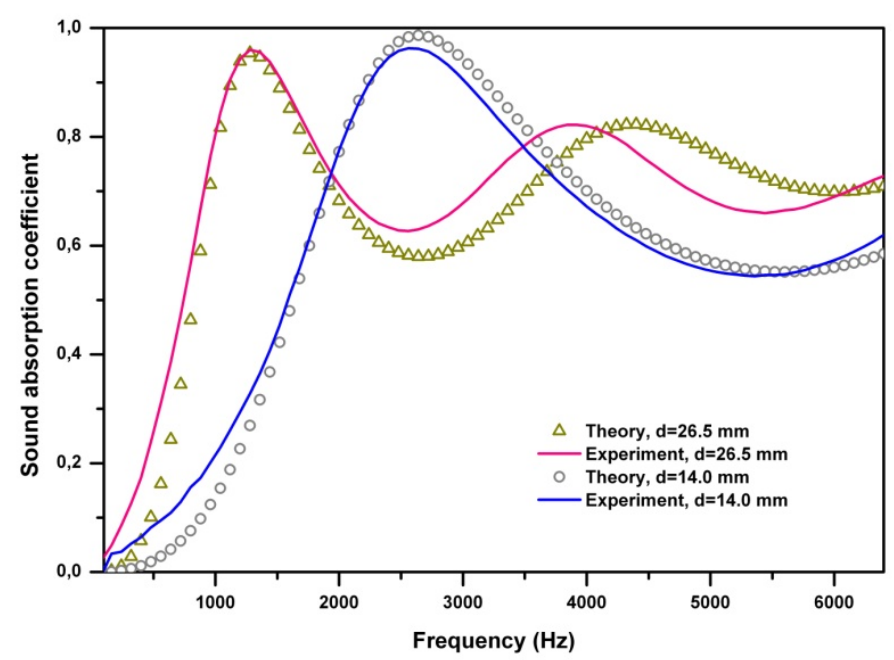

Figure 8 Comparison between the experimental results and prediction using $s_{p}=3.100$ and $s_{k}=0.350$ for the sample M-1. 


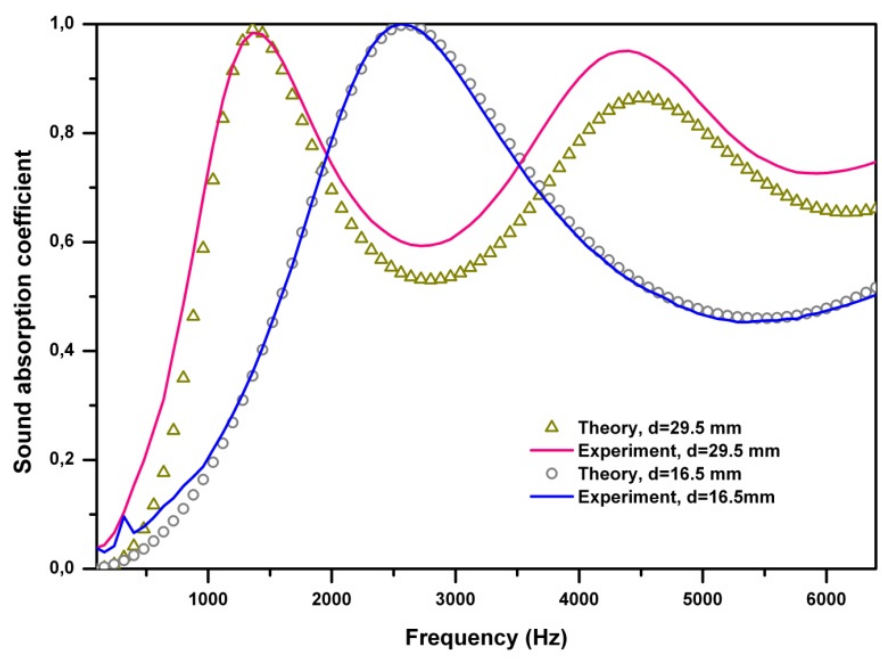

Figure 9 Comparison between the experimental results and prediction using $s_{p}=2.590$ and $s_{k}=0.285$ for the sample M-4.

The best fit values are sp and sk are 3.100 and 0.350 , respectively, for the sample M-1. For this material, composed by GTR, Vermiculite and EPS, Figure 8 shows a small discrepancy between the experimental and predicted values of the absorption coefficient.

\section{CONCLUSIONS}

This work shows an investigation of a new kind of material and its acoustical performance. The results, obtained in this paper, show a novel kind of sound absorption material with high sound absorption performance.

The use of this type of elastomeric waste offers a way of producing very absorbent materials whose acoustical absorption properties are determined by the particle size and the binder concentration.

The Champoux-Allard model has been used to predict the acoustic properties of this new porous absorber. Application of this model requires a detailed knowledge of the pore geometry but this is generally not available. Close fit, between the experimental data and the theoretical predictions, has been observed for the values of the non-acoustic parameters required by the model for samples made with recycled rubber and obtained non-acoustically. This model, constitute a good tool in order to design a new porous absorber.

These innovative sound absorbers have a positive future as it is cheaper and environmentally compared to other available materials and can adequately compete with commercially available acoustical products and, in some cases, show better performance than conventional porous absorbers.

Latin American Journal of Solids and Structures 10(2013) $585-600$ 


\section{References}

Aiello, M.A., Liuzzi, F., Centonze, G., Maffezzoli, A. (2009). Use of steel fibres recovered from waste tyres as reinforcement in concrete: pull-outbehaviour, compressive and flexural strength. Waste Management 29:1960-1970.

Barrigón Morillas, J.M., Gómez Escobar, V., Rey Gozalo G., Vílchez Gómez, R. (2010). Possible relation of noise levels in streets to the population of the municipalities in which they are located. J Acoustical Society of America 128:86-92.

Biot, M.A. (1956). The theory of propagation of elastic waves in a fluid-saturated porous solid. I. Low frequency range. J Acoustical Society of America 28:168-178.

Biot, M.A. (1956). The theory of propagation of elastic waves in a fluid-saturated porous solid. II. Higher frequency range. J Acoustical Society of America 28:179-191.

Brown, J.S. (1980). Connection between formation factor for electrical resistivity and fluid-solid coupling factors in Biot's equations for acoustic waves in fluid-filled porous media. Geophysics 45(8):1269-1275.

Champoux, Y., Stinson, M.R. (1992). On acoustical models for sound propagation in rigid frame porous materials and the influence of shape factors. J Acoustical Society of America 92:1120-1131.

ETRA. (2006). Tyre Technology International - Trends in Tyre Recycling. <http://www.etra-eu.org $>$. [accessed $28.1111]$.

Han, Z., Chunsheng, L., Kombe, T., Thong-On, N. (2008). Crumb rubber blends in noise absorption study. Materials and Structures 41:383-390.

Hong, Z., Bo, L., Guangsu, H., Jia, H. (2007). A novel composite sound absorber with recycled rubber particles. J Sound and Vibration 304:400-406.

Horoshenkov, K.V., Swift, M.J. (2000). The effect of consolidation on the acoustic properties of loose rubber granulates. Applied Acoustics 62:665-690.

ISO 10534-2. (1998). Acoustics: determination of sound absorption coefficient and impedance in impedances tubes. Part 2: transfer-function method.

Jakovljevic, B., Paunovic, K., Belojevic, G. (2009). Road-traffic noise and factors influencing noise annoyance in an urban population.Environ International 35:552-558.

Jimenez-Espadafor, F.J., Becerra Villanueva, J.A., Torres-García, M., Carvajal-Trujillo, E., Muñoz-Blanco, A. (2011). Optimal design of acoustic material from tire fluff.Materials and Design 32:3608-3616.

Johnson, D.L., Plona, T.J., Scala, C., Pasierb, F., Kojima, H. (1982). Tortuosity and acoustic slow waves.Physical Review Letters 49:1840-1844.

Li, X., Xu, H., Gao, Y., Tao, Y. (2010). Comparison of end-of-life tire treatment technologies: A Chinese case study. Waste Management 30:2235-2246.

Maderuelo-Sanz, R., Martín-Castizo, M., Vilchez-Gómez, R. (2011). The performance of resilient layers made from recycled rubber fluff for impact noise reduction. Applied Acoustics 72:823-828.

Murphy, E., King, E.A., (2011). Scenario analysis and noise action planning: Modelling the impact of mitigation measures on population exposure. Applied Acoustics 72:487-494.

Oldham, D.J., Egan, C.A., Cookson, R.D. (2011).Sustainable acoustic absorbers from the biomass.AppliedAcoustics $72: 350-363$.

Paje, S.E., Bueno, M., Terán, F., Miró, R., Pérez-Jiménez, F., Martínez, A.H. (2010). Acoustic field evaluation of asphalt mixtures with crumb rubber. Applied Acoustics 71:578-582.

Pfretzschner, J., Rodríguez, R.M. (1999). Acoustic properties of rubber crumbs.Polymertesting 18:81-92.

Rodríguez Montejano, R.M. (2004). Propiedades acústicas de caucho granular. Ph.D. Thesis, Polytechnical University of Madrid, Spain. 
Rushforth, I.M., Horoshenkov, K.V., Miraftab, M., Swift, M.J. (2005). Impact sound insulation and viscoelastic properties of underlay manufactured from recycled carpet waste. Applied Acoustics 66:731-749.

Swift, M.J., Bris, P., Horoshenkov, K.V. (1999). Acoustic absorption in recycled rubber granulates. Applied Acoustics 57:203-212.

Vasina, M., Hughes, D.C., Horoshenkov, K.V., Lapcík, Jr. L. (2006). The acoustical properties of consolidated expanded clay granulates. Applied Acoustics 67:787-796.

Zannin, P.H., Diniz, F.B., Barbosa, W.A., (2002). Environmental noise pollution in the city of Curitiba, Brazil. Applied Acoustics 63: 351-359.

Zwikker, C., Kosten, C.W. (1949). Sound Absorbing Materials, Elsevier, New York. 